\title{
Pathways of Student Stayers, Movers, and Leavers in the First Two Years of Undergraduate Engineering
}

\section{Ms. Bethany B. Smith, Arizona State University}

Bethany Smith is currently a master's student in materials science and engineering at Arizona State University. She has been involved in STEM education research since 2012 under the direction of Professor Stephen Krause. Her research interests in STEM education include faculty development, best classroom practices, and improving undergraduate engineering student retention through understanding what makes students leave engineering. She will be pursuing her PhD in Materials Science and Engineering starting in 2016 at the University of California Berkeley.

\section{Dr. Yong-Seok Park, Arizona State University}

Yong-Seok Park is currently a postdoctoral associate at Arizona State University in the STEM education research group headed by Dr. Krause. He earned his Master's degree at George Washington University and his Doctorate at the Virginia Polytechnic Institute and State University. His research interests lie in undergraduate STEM education research and engineering design education.

\section{Lydia Ross, Arizona State University}

Lydia Ross is a doctoral student and graduate research assistant at Arizona State University. She is a first year student in the Educational Policy and Evaluation program.

\section{Prof. Stephen J. Krause, Arizona State University}

Stephen Krause is professor in the Materials Science Program in the Fulton School of Engineering at Arizona State University. He teaches in the areas of introductory materials engineering, polymers and composites, and capstone design. His research interests include evaluating conceptual knowledge, misconceptions and technologies to promote conceptual change. He has co-developed a Materials Concept Inventory and a Chemistry Concept Inventory for assessing conceptual knowledge and change for introductory materials science and chemistry classes. He is currently conducting research on NSF projects in two areas. One is studying how strategies of engagement and feedback with support from internet tools and resources affect conceptual change and associated impact on students' attitude, achievement, and persistence. The other is on the factors that promote persistence and success in retention of undergraduate students in engineering. He was a coauthor for best paper award in the Journal of Engineering Education in 2013.

\section{Dr. Ying-Chih Chen, Arizona State University}

Ying-Chih Chen is an assistant professor in the Division of Teacher Preparation at Mary Lou Fulton Teachers College at Arizona State University in Tempe, Arizona.

His research takes two distinct but interrelated paths focused on elementary students' learning in science and engineering as well as in-service science teachers' professional development. The first focus involves how language as a learning tool improves students' conceptual understandings, literacy, and representation competencies in science. His second research focus is on how in-service teachers develop their knowledge for teaching science and engineering in argument-based inquiry classrooms. This research is aimed at developing measures of teachers' Pedagogical Content Knowledge (PCK) for adopting the argumentbased inquiry approach, as well as developing tools to capture the interactive nature of PCK.

\section{Prof. James A Middleton, Arizona State University}

James A. Middleton is Professor of Mechanical and Aerospace Engineering and Director of the Center for Research on Education in Science, Mathematics, Engineering, and Technology at Arizona State University. For the last three years he also held the Elmhurst Energy Chair in STEM education at the University of Birmingham in the UK. Previously, Dr. Middleton was Associate Dean for Research in the Mary Lou 
Fulton College of Education at Arizona State University, and Director of the Division of Curriculum and Instruction. He received his Ph.D. in Educational Psychology from the University of Wisconsin-Madison in 1992, where he also served in the National Center for Research on Mathematical Sciences Education as a postdoctoral scholar.

\section{Dr. Eugene Judson, Arizona State University}

Eugene Judson is an Associate Professor of for the Mary Lou Fulton Teachers College at Arizona State University. His past experiences include having been a middle school science teacher, Director of Academic and Instructional Support for the Arizona Department of Education, a research scientist for the Center for Research on Education in Science, Mathematics, Engineering and Technology (CRESMET), and an evaluator for several NSF projects. His first research strand concentrates on the relationship between educational policy and STEM education. His second research strand focuses on studying STEM classroom interactions and subsequent effects on student understanding. He is a co-developer of the Reformed Teaching Observation Protocol (RTOP) and his work has been cited more than 1500 times and his publications have been published in multiple peer-reviewed journals such as Science Education and the Journal of Research in Science Teaching.

\section{Prof. Robert J. Culbertson}

Robert J. Culbertson is an Associate Professor of Physics. Currently, he teaches introductory mechanics and electrodynamics for physics majors and a course in musical acoustics, which was specifically designed for elementary education majors. He is director of the ASU Physics Teacher Education Coalition (PhysTEC) Project, which strives to produce more and better high school physics teachers. He is also director of Master of Natural Science degree program, a graduate program designed for in-service science teachers. He works on improving persistence of students in STEM majors, especially under-prepared students and students from under-represented groups.

\section{Dr. Casey Jane Ankeny, Arizona State University}

Casey J. Ankeny, PhD is lecturer in the School of Biological and Health Systems Engineering at Arizona State University. Casey received her bachelor's degree in Biomedical Engineering from the University of Virginia in 2006 and her doctorate degree in Biomedical Engineering from Georgia Institute of Technology and Emory University in 2012 where she studied the role of shear stress in aortic valve disease. Currently, she is investigating cyber-based student engagement strategies in flipped and traditional biomedical engineering courses. She aspires to understand and improve student attitude, achievement, and persistence in student-centered courses.

\section{Prof. Keith D. Hjelmstad, Arizona State University}

Keith D. Hjelmstad is Professor of Civil Engineering in the School of Sustainable Engineering and the Built Environment at Arizona State University.

\section{Dr. Claire Y. Yan, University of British Columbia - Okanagan}

Dr. Claire Y. Yan is a senior instructor in the School of Engineering, University of British Columbia, Okanaga. She received her B.Sc. and M.Sc. degrees from Xi' an Jiaotong University, China and Ph.D. degree from University of Strathclyde, UK. Prior to joining UBC in 2008, she worked as a research scientist at Ryerson University on various projects in the area of CFD and heat and mass transfer. Dr. Yan has taught a variety of courses including fluid mechanics, fluid machines, mechanics of materials, calculus, and kinematics and dynamic. She has also developed undergraduate fluids laboratories and supervised many capstone projects. Her interest in SoTL is evidence-based teaching strategies, student engagement, faculty development, and teaching and learning communities. Dr. Yan is a registered P.Eng. with APEGBC and has served as reviewer for various international journals. 


\title{
Pathways of Student Stayers, Movers, and Leavers in the First Two Years of Undergraduate Engineering
}

\begin{abstract}
In this research paper the pathways of 720 engineering freshman entering a large, southwestern university in Fall 2007 were tracked over their first four semesters along with their academic achievement and demographic information. The same analysis was performed on 1855 engineering freshman entering the same large, southwestern university in Fall 2012. Based on their junior entry status, we characterized student pathways in their first two years in terms of stayers (stayed in engineering), movers (stayed at the university but in a different major), and leavers (left the university). Our efforts address the research question: "What role does student performance, gender, and sense of belonging have in student persistence and destination during the first two years of engineering?" The results of our work indicate that student performance, gender, and sense of belonging all influence education pathway in different ways.
\end{abstract}

\section{Background}

Retaining students in engineering through graduation is of importance for keeping the U.S. competitive in the global economy. Because of this need, there is a national call for increasing the amount of STEM (science, technology, engineering, and math) trained graduates, particularly in engineering. Yet recent studies show that engineering enrollment has declined in recent years ${ }^{1}$. Even though the rate of attrition from engineering is similar to the rate of attrition from other disciplines, students who switch majors are unlikely to pick engineering as their second major. Therefore there is high student outflow from engineering without a matching inflow, resulting in higher net attrition from engineering when compared to other disciplines ${ }^{2}$. Also, only about $50 \%$ of students entering engineering as freshman at research institutions graduate with an engineering degree ${ }^{3,4}$. All of these factors drive research efforts in understanding what factors impact retention and what can be done to increase retention in engineering.

Why students leave engineering is attributed to a multitude of reasons including curriculum overload, poor teaching, and a student's sense of belonging in engineering ${ }^{5,6}$. However, grades appear to be less of a primary cause for students leaving engineering than intuition would suggest. A U.S. Department of Education (DOE) study reported that only $8.5 \%$ of students who leave engineering do so because of grades below C. However, $98 \%$ of the students surveyed indicated poor teaching as a reason for leaving ${ }^{7}$. These results are echoed elsewhere, and we hope to compare our analyses involving grades to the ample related literature available.

In addition to how grades influence retention, this work also focuses on understanding how sense of belonging impacts retention as well. A student's sense of belonging in engineering is one of the major factors indicating success in the field ${ }^{9,}{ }^{10}$. Our study focuses on only engineering students in a large southwestern university. In particular, it examines whether reforms designed to address students' belonging could influence retention. The engineering school adopted various strategies to address attrition of its engineering students in the 1990s. Many of these changes mirrored the examples of the "ASEE Best Practices" such as formalizing tutoring opportunities, 
elucidating programs of study, and adjusting advising procedures. In 2003 the college further supported this effort by lowering the 128 credit hour graduation requirement to 120 credit hours. Reducing student workload gave them more flexibility in their scheduling, making it more feasible for them to graduate within the standard four-, five-, or six-year tracks. This is evidenced by the fact that since 2003 the percentage of students graduating in four years has risen far more dramatically than the percentage of students graduating in six years. These reforms were not always consistent across the different engineering disciplines (or even classrooms), but the college still experienced a substantial growth in its retention rates.

Starting in 2007 a more concentrated effort was made with the goal of advancing retention rates even further. Prior to these efforts, most reforms implemented were programmatic in nature and did not specifically target a student's sense of belonging within their major. To rectify this, the college instituted systemic changes to address students' feelings of displacement as first- and second-year engineering students. This new suite of strategies can be broken down as $\mathrm{Co}$ Curricular Experiences, Course Curricular Experiences, and Student Support Programs.

- Co-Curricular Experiences include undergraduate research opportunities, engineering summer camps for freshmen, and professional student societies (often specific to a student's major). The intent of these programs is for students to be able to bond with one another and with faculty outside of the classroom, all the while honing their research and professional skills.

- Course Curricular Experiences refer to two mandatory courses all engineering students in the college must take. The first is a student success course taken by all entering university students focused on time-management and study skills. The second is a revised introduction to engineering course designed for first-year students, geared toward problem-solving and team-building tasks.

- Student Support Programs are many-fold and include upper-division engineering students serving as peer mentors and undergraduate teaching assistants (UGTAs), supplemental instruction made available through an engineering-specific tutoring center, and a student residential community wherein all freshmen engineers live together in a centralized, on-campus complex. Together these policies provide both support and role models for students who may be struggling while also promoting the development of close-knit, supportive cohorts within the greater engineering community.

These different strategies and programs were made available to all engineering students, regardless of their major. Many of the strategies targeted underclassmen engineers, with the hopes of reinforcing these students' early sense of belonging within the engineering community ${ }^{11}$, as evidenced above.

Through tracking the education pathways of engineering freshman entering in 2007 and in 2012, we hope to understand how grades and sense of belonging influence retention in engineering and to answer the research question, "What role does student performance, gender, and sense of belonging have in student persistence and destination during the first two years of engineering?" 


\section{Methods}

An abbreviated interrupted time series approach was used to determine the effectiveness of this suite of strategies. Both enrollment status and retention data was available from 1998 through 2014. Using an online database called DataWarehouse, we tracked the pathways of 720 engineering freshman entering the engineering school in Fall 2007 over their first four semesters along with their academic achievement and demographic information. We performed the same type of tracking on 1855 freshman entering engineering in Fall 2012 for a comparison. In other words, we employed a quasi-experimental design using the 2007 cohort as the pre-treatment group and the 2012 cohort as the post-treatment group, the treatment being the suite of strategies aimed at increasing students' sense of belonging. We hypothesized that the two time points would show the impact of the suite of strategies aimed at increasing retention.

Based on their junior year entry status, we classified the students into three groups: stayers (stayed in engineering), movers (stayed at the university but in a different major), and leavers (left the university). These groups were chosen to match previous studies in retention in engineering ${ }^{8}$. For the movers, we also tracked what their major was at the start of their junior year. The start of junior year was the chosen as the cutoff point because previous work has shown that, in the engineering school studied, a student that remains in engineering for the first two years is likely to graduate within 6 years ${ }^{11}$. We identified the distributions of student pathways and correlated them to student performance (cumulative GPA) and gender. For leavers and movers, we kept track of their cumulative GPA when they departed from engineering. The three cumulative GPA ranges considered in this study were below $\mathrm{C}$ (below 2.0 on a 4.0 scale), at $\mathrm{C}$ (2.0-2.99), and above $\mathrm{C}$ (above a 3.0). These ranges were chosen because previous work about engineering students indicated that these three grade ranges had a large impact on who stayed in engineering based off of their first math course grade ${ }^{12}$. 


\section{Results}

Table 1 below shows the breakdown of the 2007 and 2012 engineering freshman cohorts.

\begin{tabular}{|c|c|c|c|}
\hline 2007 Cohort & Total & Male & Female \\
\hline Number of Students & 720 & 576 & 144 \\
\hline Number of Leavers & 167 & 146 & 21 \\
\hline Number of Movers & 191 & 146 & 45 \\
\hline Number of Stayers & 362 & 284 & 77 \\
\hline \% Leavers & $23 \%$ & $25 \%$ & $15 \%$ \\
\hline \% Movers & $27 \%$ & $25 \%$ & $31 \%$ \\
\hline \%Stayers & $50 \%$ & $50 \%$ & $54 \%$ \\
\hline 2012 Cohort & Total & Male & Female \\
\hline Number of Students & 1855 & 1483 & 373 \\
\hline Number of Leavers & 361 & 304 & 57 \\
\hline Number of Movers & 299 & 219 & 80 \\
\hline Number of Stayers & 1195 & 960 & 235 \\
\hline \% Leavers & $20 \%$ & $20 \%$ & $15 \%$ \\
\hline \% Movers & $16 \%$ & $15 \%$ & $22 \%$ \\
\hline \%Stayers & $64 \%$ & $65 \%$ & $63 \%$ \\
\hline
\end{tabular}

Table 1. Breakdown of the 2007 (top part of table) and the 2012 (bottom part of table) cohorts by educational pathway and gender.

One can see that retention within engineering increased over time by nearly $15 \%$ due to the change in stayers from $50 \%$ in 2007 to $64 \%$ in 2012. One interesting takeaway from the table is that women leave less and move more than their male counterparts.

Figure 1 below compares cumulative GPAs of the 3 educational pathway groups for both cohorts. 


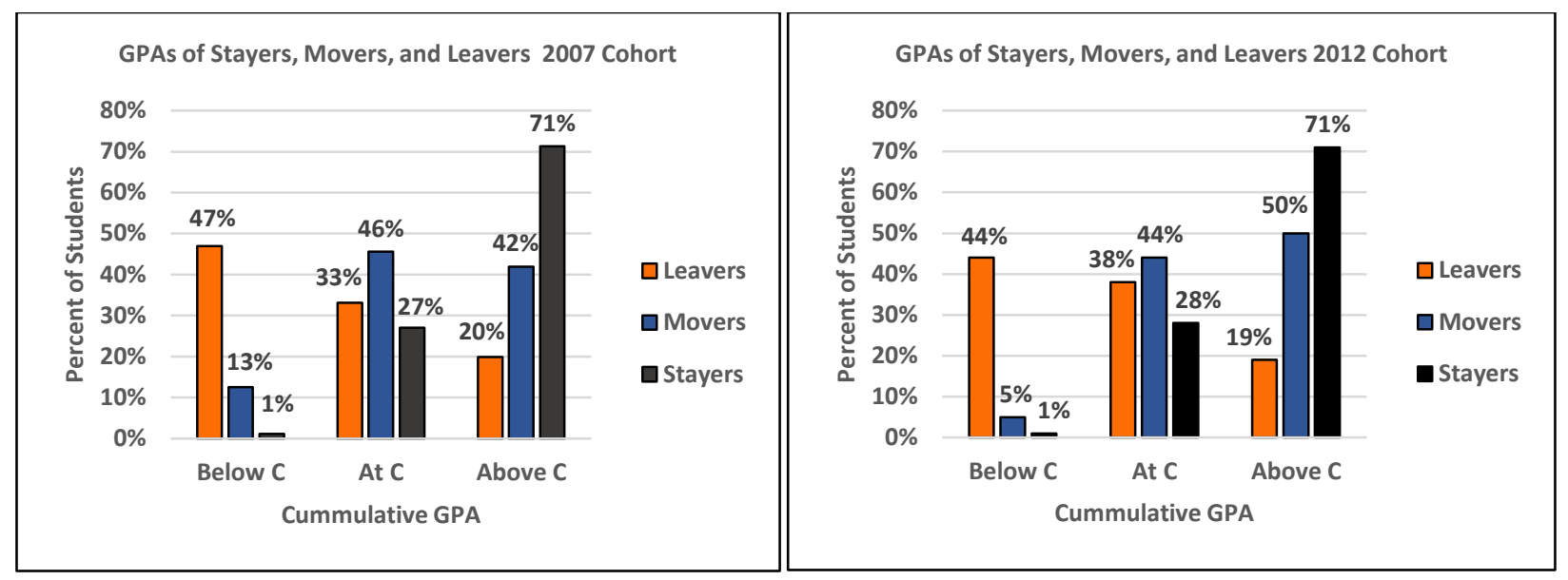

Figure 1. GPA comparisons of the stayers, movers, and leavers for the 2007 (left) and 2012 (right) cohorts. The cumulative GPAs for leavers and movers were taken the semester before they left engineering, and the cumulative GPAs for the stayers is the GPA at the end of their sophomore year.

The graphs look nearly identical, indicating that not much change in grade distribution occurred for the three groups before and after the suite of strategies. It is interesting to note that the majority of movers (about $90 \%$ ) had a cumulative GPA at or above $\mathrm{C}$ in both cohorts. Also, the leavers are fairly evenly split between below $\mathrm{C}$ and the combination of at and above $\mathrm{C}$. Both of these findings indicate that factors besides GPA influence a student's choice to leave or move.

The table below shows when both leavers and movers depart from engineering for both cohorts.

\begin{tabular}{|l|c|c|c|c|}
\hline & After First Semester & $\begin{array}{c}\text { After Second } \\
\text { Semester }\end{array}$ & $\begin{array}{c}\text { After Third } \\
\text { Semester }\end{array}$ & $\begin{array}{c}\text { After Fourth } \\
\text { Semester }\end{array}$ \\
\hline $\mathbf{2 0 0 7}$ Leavers & $33 \%$ & $39 \%$ & $17 \%$ & $11 \%$ \\
\hline 2012 Leavers & $20 \%$ & $35 \%$ & $15 \%$ & $30 \%$ \\
\hline \multicolumn{5}{|l}{} \\
\hline $\mathbf{2 0 0 7}$ Movers & $20 \%$ & $33 \%$ & $28 \%$ & $18 \%$ \\
\hline $\mathbf{2 0 1 2}$ Movers & $24 \%$ & $28 \%$ & $27 \%$ & $21 \%$ \\
\hline
\end{tabular}

Table 2. When leavers and movers depart from engineering for the 2007 and 2012 cohorts. The percentages are out of the educational pathway group (i.e. of the leavers in the 2007 cohort, 33\% of them left after their first semester in engineering). The table is grouped by educational pathway for easy comparison.

No obvious trends in the time of departure from engineering can be identified by examining Table 2, which leads us to suspect that there is not a specific semester that students after which students are most likely to depart and that there was not change in when students depart from engineering over time. 
In addition, we examined which disciplines movers moved to. Although some students switched majors more than once, we are reporting the major that the movers had at the start of their junior year. Figure 2 below is a pie-chart of the disciplines that movers move to for both cohorts. Individual majors were grouped into the following disciplines: Business, Physical/Life Sciences \& Tech/Math (i.e. physics, biology, etc.), Social Sciences/Education (i.e. political science, psychology, etc.), Humanities/Art (i.e. English, communication, etc.), and Other. These groups will be abbreviated as B, PLSTM, SS/E, H/A, and O respectively.

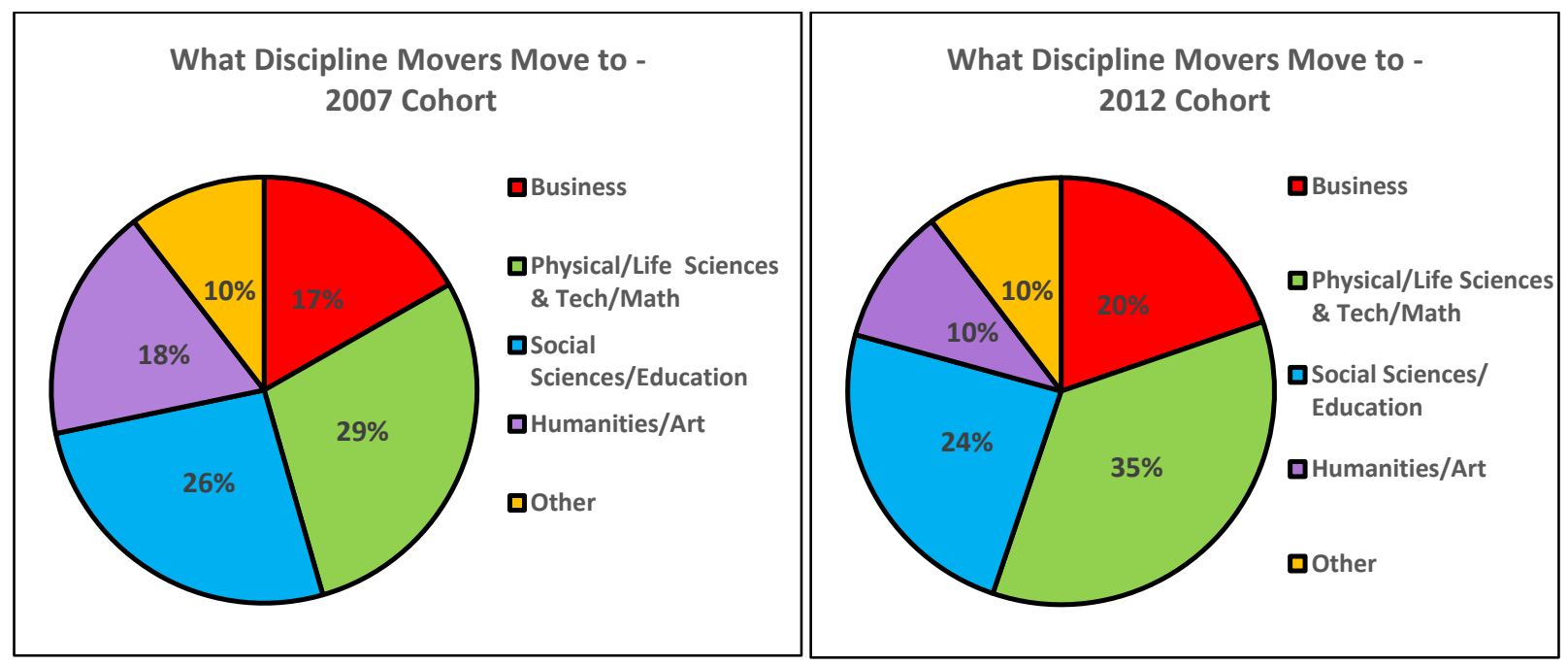

Figure 2. Distribution of disciplines that movers selected at the start of their junior year for the 2007 (left) and 2012 (right) cohorts.

It appears that more movers in the 2012 cohort moved to technology-oriented fields in 2012 and less to humanities/arts when compared to the 2007 cohort. Besides that, the distributions are similar indicating little difference over time in movers' discipline selection. We also examined what role cumulative GPA has on what major movers select by their junior year, and the results did not match the results of previous works ${ }^{8}$. Table 3 displays the grade distributions for movers moving to each of the discipline groups from Figure 2. 


\begin{tabular}{|c|c|c|c|c|c|}
\hline 2007 Cohort & B & PLSTM & SS/E & H/A & O \\
\hline Below C & $3 \%$ & $11 \%$ & $18 \%$ & $15 \%$ & $15 \%$ \\
\hline At C & $25 \%$ & $51 \%$ & $52 \%$ & $53 \%$ & $35 \%$ \\
\hline Above C & $72 \%$ & $38 \%$ & $30 \%$ & $32 \%$ & $50 \%$ \\
\hline Average GPA & 3.2 & 2.8 & 2.6 & 2.8 & 2.9 \\
\hline & & & & & H/A \\
\hline 2012 Cohort & B & PLSTM & SS/E & $3 \%$ & $0 \%$ \\
\hline Below C & $2 \%$ & $8 \%$ & $8 \%$ & $45 \%$ & $68 \%$ \\
\hline At C & $17 \%$ & $49 \%$ & $50 \%$ & $55 \%$ & $32 \%$ \\
\hline Above C & $81 \%$ & $43 \%$ & $42 \%$ & 3.0 & 2.7 \\
\hline Average GPA & 3.2 & 2.9 & 3.1 & \\
\hline
\end{tabular}

Table 3. Grade distributions and average last cumulative GPA in engineering for movers moving into Business (B), Physical/Life Sciences \& Tech/Math (PLSTM) Social Sciences/Education (SS/E), Humanities/Art (H/A) and Other (O).

In previous works, movers going to business had a lower average cumulative GPA distribution than those going to physical sciences ${ }^{8}$. In our study, however, movers going to business had the highest average cumulative GPA and the overall most right-shifted grade distribution. There are many possible reasons for the differences between our study and previous works in this area which will be explained in the discussion section below.

Finally, the education pathways of the 2007 and 2012 engineering freshman cohorts was analyzed by gender as well. Table 1 shows the summary of education paths for both cohorts and for both men and women. Figure 3 below shows the grade distributions for male and female stayers at the end of their sophomore year.

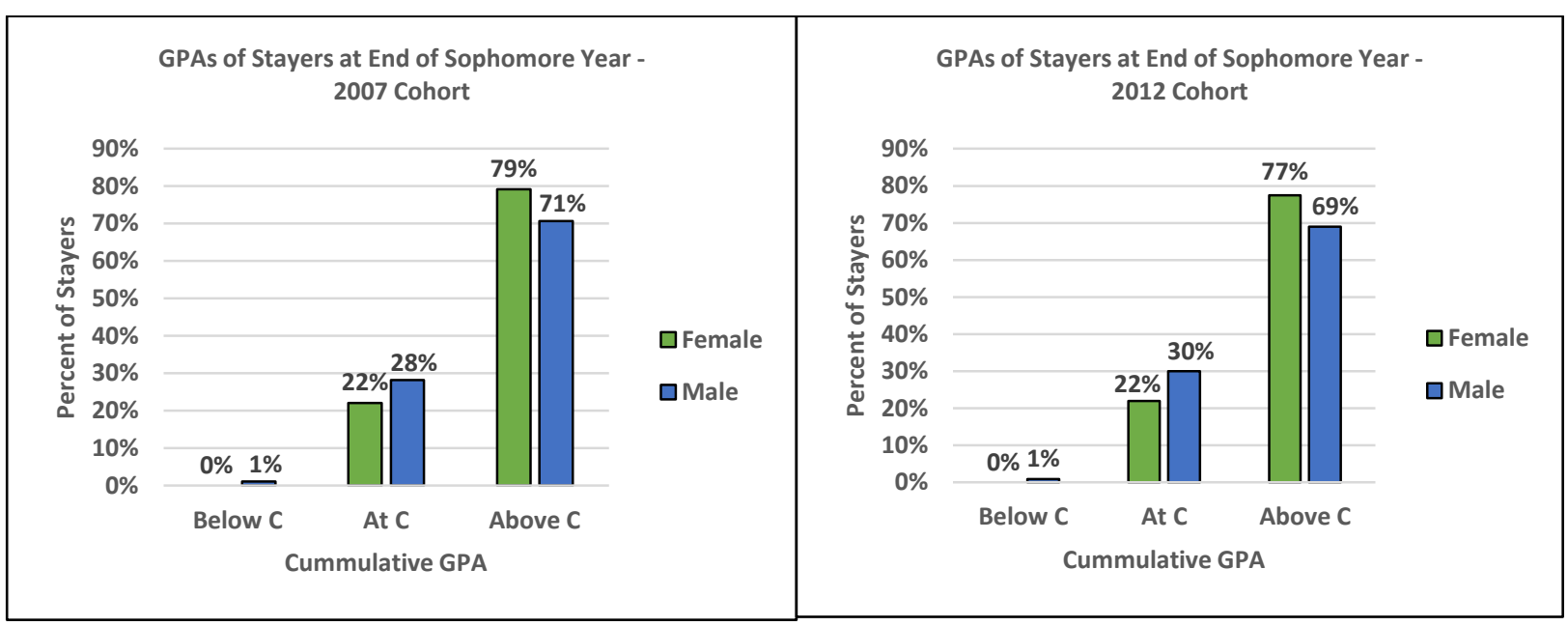


Figure 3. Grade distributions for male and female stayers at the end of their sophomore years for the 2007 (left) and 2012 (right) cohorts.

Interestingly, women stayers have statistically significantly ( $\mathrm{p}$ value less than 0.05 ) higher GPAs than men in both cohorts, suggesting that GPA may have a more prominent influence on women staying in engineering than with men. Corresponding trends can be seen in the leavers' grade distribution in Figure 4 below. Women leavers have lower GPAs than their male counterparts, again indicating that GPA may have a higher impact on women's' education pathway than on men's.

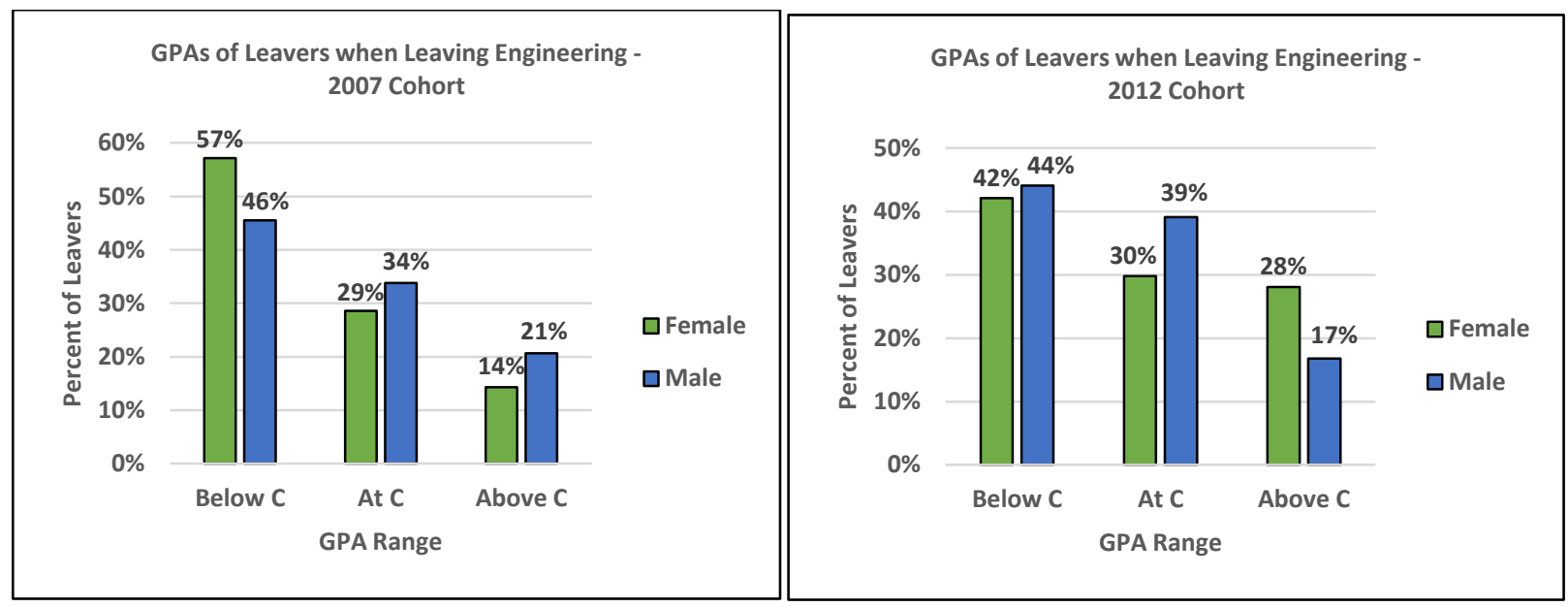

Figure 4. Grade distribution of male and female leavers when departing from engineering for the 2007 (left) and 2012 (right) cohorts.

Another interesting finding in terms of GPA is the difference in GPA distributions of male and female movers. Figure 5 below shows the grade distributions of male and female movers.

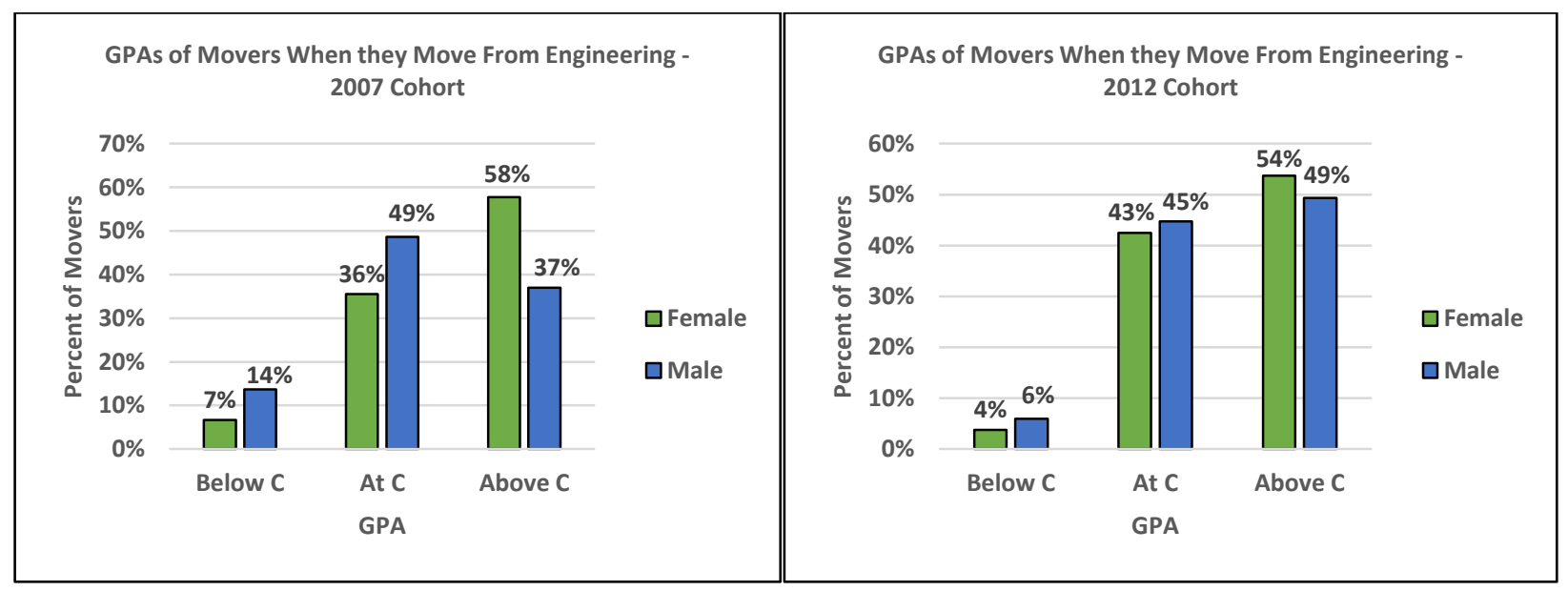

Figure 5. Grade distributions for male and female movers when departing from engineering for the 2007 (left) and 2012 (right) cohorts.

Figure 5 shows that female movers have higher cummulative GPAs when departing from engineering. Figure 1 already demonstrated evidence for the claim that GPA is probably not the 
primary reason movers move. Figure 5 supports the claim that GPA is even less of a reason female movers move when compared to male movers. We suspect that either a lack of sense of belonging in women or a chilly climate towards women in engineering may be responsible for the for the difference (though we can cannot be sure). This will be explored further in the discussion section.

Table 4 below shows what disciplines male and female movers select by the start of their junior year for the two cohorts. There does not appear to be much difference between men's and women's discipline selection in either cohort. However when compared to the 2007, there was a sizeable increase in females going to PLSTM majors in 2012.

\begin{tabular}{|c|c|c|c|c|}
\hline \multirow{2}{*}{} & \multicolumn{2}{|c|}{ 2007 Cohort } & \multicolumn{2}{c|}{ 2012 Cohort } \\
\cline { 2 - 5 } & Female & Male & Female & Male \\
\hline B & $9 \%$ & $19 \%$ & $14 \%$ & $22 \%$ \\
\hline PLSTM & $24 \%$ & $30 \%$ & $45 \%$ & $32 \%$ \\
\hline H/A & $24 \%$ & $27 \%$ & $26 \%$ & $23 \%$ \\
\hline O & $22 \%$ & $16 \%$ & $9 \%$ & $11 \%$ \\
\hline
\end{tabular}

Table 4. Distribution of selected disciplines for male and female movers moving into Business (B), Physical/Life Sciences \& Tech/Math (PLSTM) Social Sciences/Education (SS/E), Humanities/Art (H/A) and Other $(\mathrm{O})$.

One last item we examined was the grade distributions of male and female movers for both cohorts. Table 5 below shows both the discipline selected and GPA when departing from engineering for male and female movers. 


\begin{tabular}{|c|c|c|c|c|c|c|c|c|c|c|}
\hline 2007 Cohort & \multicolumn{2}{|c|}{ B } & \multicolumn{2}{|c|}{ PLSTM } & \multicolumn{2}{|c|}{ SS/E } & \multicolumn{2}{|c|}{ H/A } & \multicolumn{2}{|c|}{$\mathbf{O}$} \\
\hline & Female & Male & Female & Male & Female & Male & Female & Male & Female & Male \\
\hline Below C & $0 \%$ & $4 \%$ & 0 & $14 \%$ & $9 \%$ & $21 \%$ & $10 \%$ & $17 \%$ & $11 \%$ & $18 \%$ \\
\hline At $C$ & $50 \%$ & $21 \%$ & $18 \%$ & $59 \%$ & $36 \%$ & $56 \%$ & $40 \%$ & $58 \%$ & $44 \%$ & $27 \%$ \\
\hline Above C & $50 \%$ & $75 \%$ & $82 \%$ & $27 \%$ & $55 \%$ & $23 \%$ & $50 \%$ & $25 \%$ & $44 \%$ & $55 \%$ \\
\hline Average GPA & 3.0 & 3.2 & 3.4 & 2.7 & 3.1 & 2.5 & 3.0 & 2.7 & 2.9 & 2.8 \\
\hline 2012 Cohort & 1 & & PLS & & Ss & & & & C & \\
\hline & Female & Male & Female & Male & Female & Male & Female & Male & Female & Male \\
\hline Below C & $9 \%$ & $0 \%$ & $3 \%$ & $10 \%$ & $0 \%$ & $12 \%$ & $14 \%$ & $0 \%$ & $0 \%$ & $0 \%$ \\
\hline At $\mathrm{C}$ & $9 \%$ & $19 \%$ & $50 \%$ & $49 \%$ & $38 \%$ & $55 \%$ & $43 \%$ & $42 \%$ & $80 \%$ & $65 \%$ \\
\hline Above C & $82 \%$ & $81 \%$ & $47 \%$ & $41 \%$ & $62 \%$ & $33 \%$ & $43 \%$ & $58 \%$ & $20 \%$ & $35 \%$ \\
\hline Average GPA & 3.3 & 3.2 & 3.0 & 2.8 & 3.2 & 2.8 & 2.9 & 3.1 & 2.5 & 2.8 \\
\hline
\end{tabular}

Table 5. Grade distributions for male and female movers moving into Business (B), Physical/Life Sciences \& Tech/Math (PLSTM) Social Sciences/Education (SS/E), Humanities/Art (H/A) and Other (O for both the 2007 (top part of table) and 2012 (bottom part of table) cohorts. The cumulative GPAs were taken their last semester in engineering.

Looking at Table 5, there do not appear to be any major differences between the average GPAs of male and female movers that selected a particular discipline. There also doesn't appear to be change between the cohorts in terms of GPA and discipline selected for both male and female movers. Table 5 is evidence that there is not much difference between male and female mover GPAs for either cohort. Additionally, there is also not much change between cohorts GPAs for each discipline group when keeping gender constant. Overall, gender does not seem to be a major factor in what discipline a mover moves to; GPAs between male and female movers is nearly the same, and there is not much change in GPAs for each discipline group when considering cohorts controlled for gender.

\section{Discussion}

Recall that the research question is "What role does student performance, gender, and sense of belonging have in student persistence and destination during the first two years of engineering?" This discussion will focus on each of the three areas (i.e. performance as measured by cumulative GPA, gender, and sense of belonging) individually.

From Table 1, one can clearly see that retention for all students increased from about $50 \%$ to $65 \%$ despite increasing enrollment. This fact suggests that the suite of strategies most likely 
played a role in increasing retention over time. Another likely factor in the increasing retention over time is efforts by the university as a whole to increase retention. However, even with the other factors, $15 \%$ is large enough of an increase to suggest that the suite of strategies played a role in increasing retention, and at least the suite didn't harm retention either way. The suite of strategies did not appear to have a role in GPA between the cohorts, when people depart from engineering, or what disciplines movers moved to as evidenced in Figures 1 and 2 and Table 2 (as expected.) Overall the suite of strategies was successful in increasing retention when considering the student body as a whole. The interested reader can see Judson et. $\mathrm{al}^{11}$ for a more detailed examination of the suite of strategies effect on retention for different student subgroups.

The apparent role of GPA in educational pathways is mixed. On one hand, about $90 \%$ of movers and $50 \%$ of leavers had GPAs at or above C, indicating that GPA is not the main factor if a student moves from engineering, and that other factors besides GPA play a role in a student's educational pathway. This finding is consistent with the literature. A 2010 study by Eris surveyed a cohort of engineering freshman 7 times over their 4 years in college and found that motivation to study engineering, confidence in math and science skills, intention to study engineering, and financial difficulties as reasons for non-persistence in engineering ${ }^{13}$, which demonstrates the variety of reasons that students depart from engineering. Though we did not survey the students examined in our study, we expect similar variation in reasons for moving or leaving from engineering. However, it is important to note that the majority of stayers did have a GPA above C. Although GPA is probably not the main reason a student moves from engineering, it may be one of the main reasons a student stays in engineering or leaves the university. This finding is consistent with our previous work that relates retention to academic performance $^{12}$.

The destination of movers is consistent when comparing the 2007 and 2012 cohorts. However, this works demonstrates that those moving into business had higher GPAs departing from engineering than those moving into PLSTM majors, which is inconsistent with previous works ${ }^{1}$. There are many possibilities for this discrepancy, including sample size and business school reputation at the college examined. The study "Grade-Point Average, Changes of Major, and Majors Selected by Students Leaving Engineering” by Ohland et al. ${ }^{8}$ included engineering students from many schools whereas our study included students from only one large, southwestern university. Also, the business school at the sampled university has a high ranking program with a minimum transfer cumulative GPA of 3.0 (currently) ${ }^{14}$. Therefore, it makes sense that students moving into business would have higher GPAs than other disciplinary groups. However, GPA does not appear to have much impact on what discipline a student moves to overall, as seen in Table 3.

The role of gender in educational pathway is pronounced when considering GPA. Female stayers had statistically significantly higher grades than male stayers in both cohorts, which suggests that GPA plays a larger role in women staying in engineering than in men. In addition, gender did not appear to be a factor in what discipline movers moved to for either cohort. Female movers had higher average cumulative GPAs than male movers for both cohorts, indicating that GPA is not as significant of a factor in moving when compared to men. We expect that this is because of 
a lack of sense of belonging. Previous work about engineering students at the university demonstrated that the suite of strategies mentioned in this study did not impact the rate of retention within engineering for women ${ }^{2}$. Also, many previous works show that women experience an unwelcoming, chilly climate in STEM more often than men ${ }^{15,16}$, and this may be the case at the large, southwestern university studied as well, which would decrease the sense of belonging for women.

\section{Conclusions}

This study answered the research question "What role does student performance, gender, and sense of belonging have in student persistence and destination during the first two years of engineering?" Student performance as measured by cumulative GPA has an impact on education pathway. Although GPA is probably not the main reason a student moves from engineering, it may be one of the main reasons a student stays in engineering or leaves the university. Gender has an influence on education pathway with respect to GPA. Female stayers had statistically significantly higher grades than male stayers in both cohorts, which suggests that GPA plays a larger role in women staying in engineering than men. In addition, gender did not appear to be a factor in what discipline movers moved to for either cohort. Female movers had higher average cumulative GPAs than male movers for both cohorts, indicating that GPA is not as significant of a factor in moving when compared to men. Finally, sense of belonging has an impact on education pathway as well. The suite of strategies introduced in 2007 appears to have played a role in increasing retention overall within engineering, and because the components of this suite of strategies have shown to increase sense of belonging in students ${ }^{11}$, we suspect that the increase in overall retention was impacted by an increase in sense of belonging. To benefit sense of belonging and reduce chilly-climate issues that appear to impact females' pathways more than males', it is recommended that faculty development, particularly for creating an inclusive classroom environment, be implemented at the institution studied.

\section{Acknowledgement}

This material is based upon work supported by the National Science Foundation under Grant No. 1226586.

\section{Bibliography}

1 M. W. Ohland, G. Zhang, B. Thorndyke and T. J. Anderson, "Grade-Point Average, Changes of Major, and Majors Selected by Students Leaving Engineering," in Frontiers in Education, Savannah, 2004.

2 E. Judson, B. Smith, J. Erzen, S. Krause, J. Middleton and R. Culbertson, "What is the Effect of Establishing Programs that Address Sense of Belonging on Undergraduate Engineering Retention?," in Frontiers in Education, El Paso, 2015.

3 K. Rask, "Attrition in STEM fields at a liberal arts college: The importance of grades and pre-collegiate preferences," Economics of Education Review, vol. 29, no. 6, pp. 892-900, 2010.

4 X. Chen, "STEM Attrition: College Students' Paths into and out of STEM Fields.," National Center for 
Education Statistics, 2013. http://nces.ed.gov/pubs2014/2014001rev.pdf

5 M. W. Ohland, S. D. Sheppard, G. Lichtenstein, O. Eris, D. Chachra and R. A. Layton, "Persistence, engagement, and migration in engineering programs," Journal of Engineering Education, vol. 97, pp. 259-278, 2008 .

6 M. W. Ohland, S. D. Sheppard, G. Lichtenstein, O. Eris, D. Chachra and R. A. Layton, "Race, gender, and measures of success in engineering education," Journal of Engineering Education, vol. 100, pp. 225-252, 2011.

7 M. Matthews, "Keeping Students in engineering: a research-to-practice brief," in American Society of Engineering Education, 2012.

8 E. Seymour, Testimony offered to the Research Subcommittee of the Committee on Science of the U.S. House of Representatives hearing on Undergraduate Science, Mathematics, and Engineering Education: What's Working?, 2006.

9 C. Adelmann, "Women and Men of the Engineering Path: A Model for Analyses of Undergraduate Careers.," 1998.

10 T. Freeman, L. Anderman and J. Jensen, "Sense of Belonging in College Freshman at the Classroom and Campus Levels.," The Journal of Experimental Education, vol. 75, no. 3, pp. 203-220, 2007.

11 M. Hoffman, J. Richmond, J. Morrow and K. Salomone, "Investigating "Sense of Belonging" in First-Year College Students," Journal of College Student Retention: Research Theory and Practice, vol. 4, no. 3, pp. 227256, 2002.

12 J. Middleton, S. Krause, S. Maass, K. Beeley, J. Collofello and R. Culbertson, "Early Course and Grade Predictors of Persistence in Undergraduate Engineering Majors," in Frontiers in Education, 2014.

13 O. Eris, D. Chachra, H. L. Chen, S. Sheppard, L. Ludlow, C. Rosca, T. Bailey and G. Toye, "Outcomes of a Longitudinal Administration of the Persistence in Engineering Survey," Journal of Engineering Education, vol. 99, no. 4, pp. 371-395, 2010.

14 A. S. University, "W.P. Carrey School of Business Admission Requirements," [Online]. Available: https://wpcarey.asu.edu/undergraduate-degrees/admission-requirements.

15 D. Collins, A. E. Bayer and D. A. Hirschfeld, "Engineering Education for Women: A Chilly Climate?," in Women in Engineering COnference, 1996.

16 M. H. Washburn and S. G. Miller, "Still a chilly climate for women students in technology: A case study," Women, gender, and technology, pp. 60-79, 2006. 